\title{
Estudios
}

\section{La punibilidad de los delitos de injuria y calumnia en personas fallecidas}

\section{Punishability of slander and libel crimes in deceased individuals}

Ludy Yadira Chacón Palomino ${ }^{1}$

Sergio Andrés López Zamora ${ }^{2}$

Recepción: 16/01/2021 • Aprobación: 23/02/2021 • Publicación: 17/09/2021

Para citar este artículo

Chacón Palomino, L. Y., \& López Zamora, S. A. (2021). La punibilidad de

los delitos de injuria y calumnia en personas fallecidas. Dos mil tres mil,

23, e308. https://doi.org/10.35707/dostresmil/23308

\section{@) $(\Theta \Theta \Theta$}

\footnotetext{
${ }^{1}$ Programa de Derecho y Ciencias Políticas de la Universidad de Boyacá (Colombia). ORCID: 0000-0002-5206-1425. Correo electrónico: lychacon@uniboyaca.edu.co

${ }^{2}$ Profesor investigador de la Fundación Universitaria Juan de Castellanos, Tunja, Colombia. Investigador Junior (IJ) categorizado por Colciencias. ORCID: 0000-0003-1350-6310. Correo electrónico: abogadosergiolopez@gmail.com
} 
Resumen. En el presente artículo se propone la viabilidad de que los delitos de injuria y calumnia - que en Colombia protegen el bien jurídico de la integridad moral - tengan connotaciones penales cuando sean cometidos en contra de personas fallecidas, proponiendo como sujeto pasivo al difunto y víctimas a sus familiares directos, a partir de la interpretación que recogió la Corte Constitucional de Colombia en la Sentencia T-007 de 2020, en la que se tuteló a sus familiares la honra, el buen nombre, la intimidad y la imagen de una persona fallecida.

Abstract. This article proposes the viability of slander and libel crimes - which in Colombia protect the legal good of moral integrity-having criminal connotations when they are committed against deceased individuals, proposing the deceased as a taxable person, and his/her direct relatives as victims, based on the interpretation taken by the Constitutional Court of Colombia in Sentence T-007 of 2020, in which the honor, good name, privacy, and image of a deceased individual were safeguarded.

Palabras claves

Injuria, calumnia, personas fallecidas, integridad moral, patrimonio moral.

Key words

Slander, libel, deceased individuals, moral integrity, moral patrimony. 


\section{Introducción}

El presente artículo contiene un estudio de tipo básico-jurídico, habida cuenta que desarrolla un análisis normativo de los delitos de injuria y calumnia que en Colombia tutelan el bien jurídico de la integridad moral. Para dicho fin, se utilizaron fuentes secundarias de investigación: normativa, jurisprudencial y doctrinal, aplicables al tema.

A partir de lo anterior, el artículo responde a la pregunta: ¿son punibles los delitos de injuria y calumnia cometidos sobre personas fallecidas? Planteamiento que responde al objetivo general de determinar la punibilidad de los tipos penales de injuria y calumnia cometidos sobre personas fallecidas.

Para desarrollar el objetivo general del artículo, se postularon tres objetivos específicos, a saber: 1. Establecer la noción del bien jurídico de la integridad moral en Colombia; 2. Identificar un concepto constitucional de integridad moral en personas fallecidas; $y$, 3. Proponer la punibilidad de los delitos de injuria y calumnia en personas fallecidas.

El esquema sugerido empleó un método inductivo de investigación, pues el análisis efectuado parte de las consideraciones particulares realizadas por la Corte Constitucional de Colombia en la Sentencia T-007 de 2020, para — tras el análisis propuesto- poder llegar a conclusiones generales aplicables en el marco normativo colombiano.

\section{El bien jurídico de la integridad moral}

En los derechos esenciales del hombre encontramos el derecho a la integridad personal, el cual está compuesto por la garantía de la integridad física, psíquica y moral. La integridad personal ha sido reconocida en el ámbito internacional como un derecho fundamental. La Convención Americana de Derechos Humanos, en su artículo 5.1 ha señalado que "toda persona tiene derecho a que se respete su integridad física, psíquica y moral". La integridad física se refiere al cuidado y conservación del cuerpo humano, la integridad psíquica a la preservación de sus facultades intelectuales y emocionales, y la integridad moral hace referencia al derecho que tiene cada ser humano de desarrollar su vida de una forma libre de acuerdo con sus creencias y valores personales; es decir, que la protección de este derecho es primordial e inicia con el respeto a la vida y este no tendrá limitación alguna.

Para la Corte Constitucional, en la Sentencia T-123 de 1994 se menciona que el derecho a la integridad moral "consiste en el reconocimiento, respeto y promoción que se le debe a todo individuo de la especie humana de su plenitud y totalidad espiritual con el fin de que su existencia sea conforme a la dignidad personal".

Así mismo, la Corte Suprema de Justicia, Sala de Casación Penal, en Sentencia SP111432016 Radicación 42.706, señala que el derecho fundamental a la integridad moral resulta natural a la persona misma, atendiendo el sentido antropocéntrico constitucional, en los siguientes términos: 
El derecho fundamental a la integridad moral es inherente a la persona misma en tanto el hombre es el valor supremo de la Nación constituida como Estado. Su protección se funda en el respeto a la dignidad humana cualidad intangible del ser humano y por tanto no susceptible de ser desplazada por otros valores o principios, perspectiva desde la cual el honor y la honra, constituyen el contenido fundamental de la integridad moral y son componente innato, absoluto, inmutable, irrenunciable, inalienable, indisponible y extrapatrimonial del derecho subjetivo privado, a ser respetado frente a las agresiones ilegítimas de los demás.

Así, comprenderíamos a la integridad moral como un bien jurídico natural de la persona, con carácter de fundamental y que surge como una de las tres esferas de la integridad personal (junto con la integridad física y psíquica), de tal suerte que su protección haya tomado cierto protagonismo desde el cambio constitucional que sustituyó el eje central estatal por el de la persona humana, que se ha visto con el tránsito de la Constitución Política de 1886 a la de 1991.

La inspiración que surge de la Carta Magna termina siendo acatada por el legislador penal, como se hace perceptible en el Capítulo V del libro II, artículos 220 a 228 de la Ley 599 de 2000, que tutelan al bien jurídico de la integridad moral, cuyos tipos penales centrales son la injuria (artículo 220) y la calumnia (artículo 221).

En particular, la Corte Constitucional en Sentencia C-417 de 2009 pautó la diferencia entre una y otra conducta, al identificar que el "imputar hechos delictivos falsos concretos, a sabiendas de que no son ciertos, es calumniar, mientras que hacer imputaciones o afirmaciones deshonrosas indeterminadas, o enrostrar condiciones de inferioridad, aunque sean verdaderas, es injuriar".

Abordada la definición como bien jurídico de la integridad moral y diferenciadas las conductas punibles que la tutelan, resulta prudente efectuar algunas precisiones en cuanto a sus elementos estructurales principales, para una debida comprensión previa al análisis central de la investigación, proponemos la siguiente Tabla: 
Tabla 1. Elementos estructurales de los tipos de injuria y calumnia

Artículo 220. Injuria. "El que haga a otra persona imputaciones deshonrosas, incurrirá en prisión de dieciséis (16) a cincuenta y cuatro (54) meses y multa de trece punto treinta y tres (13.33) a mil quinientos (1500) salarios mínimos legales mensuales vigentes" (Código Penal).

\begin{tabular}{|c|c|c|}
\hline Clasificación & Tipo objetivo & Tipo subjetivo \\
\hline $\begin{array}{l}\text { Delito de mera } \\
\text { conducta }\end{array}$ & $\begin{array}{c}\text { Sujeto activo: indeterminado singular. } \\
\text { Sujeto pasivo: indeterminado. } \\
\text { Verbo rector: hacer a otro -imputaciones } \\
\text { deshonrosas-. } \\
\text { Elementos descriptivos: no presenta. } \\
\text { Objeto jurídico: derechos del patrimonio moral. } \\
\text { Objeto material: sujeto sobre quien recae } \\
\text { la difamación. } \\
\text { Tentativa: no admite. } \\
\text { Coparticipación: admite determinación. }\end{array}$ & $\begin{array}{l}\text { Modalidad dogmática: } \\
\text { doloso a nivel } \\
\text { normativo. } \\
\text { Ingrediente subjetivo: } \\
\text { no aplica. }\end{array}$ \\
\hline \multicolumn{3}{|c|}{$\begin{array}{l}\text { Artículo 221. Calumnia. "El que impute falsamente a otro una conducta típica, incurrirá en prisión de } \\
\text { dieciséis (16) a setenta y dos (72) meses y multa de trece punto treinta y tres (13.33) a mil quinientos } \\
\text { (1500) salarios mínimos legales mensuales vigentes" (Código Penal). }\end{array}$} \\
\hline Clasificación & Tipo objetivo & Tipo subjetivo \\
\hline $\begin{array}{c}\text { Delito de mera } \\
\text { conducta }\end{array}$ & $\begin{array}{c}\text { Sujeto activo: indeterminado singular. } \\
\text { Sujeto pasivo: indeterminado. } \\
\text { Verbo rector: hacer a otro -imputaciones falsas de } \\
\text { una conducta punible-. } \\
\text { Elementos descriptivos: no presenta. } \\
\text { Objeto jurídico: derechos del patrimonio moral. } \\
\text { Objeto material: sujeto sobre quien recae } \\
\text { la difamación. } \\
\text { Tentativa: no admite. } \\
\text { Coparticipación: admite determinación. }\end{array}$ & $\begin{array}{l}\text { Modalidad dogmática: } \\
\text { doloso a nivel } \\
\text { normativo. } \\
\text { Ingrediente subjetivo: } \\
\text { no aplica. }\end{array}$ \\
\hline
\end{tabular}

Fuente: autores

\section{La integridad moral en personas fallecidas}

Una vez establecida la noción del bien jurídico de la integridad moral en Colombia, así como de los tipos penales de injuria y calumnia, podemos abordar el segundo objetivo específico de este artículo, que consiste en identificar un concepto constitucional de la integridad moral en personas fallecidas.

Para ello, abordaremos el análisis realizado por la Corte Constitucional colombiana en la Sentencia T-007 de 2020, en la que los familiares de una persona asesinada en el municipio de 
Paz de Ariporo (Casanare), presentaron una acción de tutela en contra de un periódico de alta difusión, por la publicación sin autorización previa de la fotografía del féretro, en el que se resalta su rostro, así como la publicación de información que no correspondió con la realidad y que en todo caso, toda información relacionada solo debía estar en custodia de la Fiscalía General de la Nación (órgano persecutor de la acción penal en Colombia).

Tras un extenso procedimiento que afrontó varias nulidades por errores procedimentales se niega el amparo, llegando para su revisión a la Sala Octava de Revisión de la Corte Constitucional, la que finalmente concede el amparo de los derechos fundamentales del difunto, así como los de sus familiares accionantes (cónyuge e hijos).

El fundamento de la decisión recoge el que consideramos es el concepto constitucional vigente de la integridad moral en personas fallecidas, que se fragmenta en los derechos a la honra, al buen nombre, a la imagen y a la intimidad, que indivisiblemente deben estudiarse para responder al problema planteado.

\subsection{Los derechos a la honra y al buen nombre}

Para comprender el alcance de estos derechos, es preciso partir del reconocimiento internacional de la Declaración Universal de Derechos Humanos (The Universal Declaration of Human Rights), en la que se indica que nadie será objeto de injerencias arbitrarias o ataques a su honra o a su reputación (artículo 12); términos equivalentes recogidos por el Pacto Internacional de Derechos Civiles y Políticos (International Covenant on Civil and Political Rights, artículo 17), que a su vez se encuentran en el Pacto de San José de Costa Rica (American Convention of Human Rights), que se opone a ataques ilegales a la honra y a la reputación (artículo 11).

En el aspecto constitucional, la Carta Política de Colombia dispone como un deber estatal la garantía de protección de la honra (artículo 2), consagrándola como un derecho fundamental (artículo 21), con un carácter inviolable (artículo 42). Nociones recogidas por la jurisprudencia de la Corte Constitucional desde la Sentencia T-411 de 1995, al entenderla como la estimación con la que cada persona debe ser tenida en sociedad, por parte de quienes la conocen y le tratan, en razón a su dignidad humana; siendo, por consiguiente, un derecho que "debe ser protegido con el fin de no menoscabar el valor intrínseco de los individuos frente a la sociedad y frente a sí mismos, y garantizar la adecuada consideración y valoración de las personas dentro de la colectividad".

Por lo anterior, la Sentencia T-022 de 2017 reconoce que su vulneración se produce "cuando se expresan conceptos u opiniones que generan un daño moral tangible al sujeto afectado", siempre que la lesión moral no dependa de una impresión personal subjetiva de su titular, sino más bien de un carácter que objetivamente lesione a este derecho (como se concluye de la Sentencia T-714 de 2010).

Por su parte, el derecho al buen nombre es reconocido por la Constitución Política (artículo 15), con una prerrogativa de respeto y protección estatal, que ha llevado a ser interpretado 
por la Corte Constitucional como "la reputación, o el concepto que de una persona tienen los demás y que se configura como derecho frente al detrimento que pueda sufrir como producto de expresiones ofensivas o injuriosas o informaciones falsas o tendenciosas" (Sentencia C-489 de 2002).

Así, es un elemento estructural del patrimonio moral que se verá vulnerado cuando sin justificación ni causa cierta y real, se propague públicamente información falsa o errónea que distorsione la imagen del sujeto, y que por tanto, "tienden a socavar el prestigio o la confianza de los que disfruta del entorno social en cuyo medio actúa, o cuando en cualquier forma se manipula la opinión general para desdibujar su imagen" (Sentencia T-471 de 1994).

Conforme con lo anterior, tanto el derecho a la honra como al buen nombre hacen parte del patrimonio moral, identificando al primero a partir de aspectos personales y comportamentales privados del sujeto; y al segundo, a partir de aspectos reputacionales de su conducta en sociedad. En particular, la Sentencia T-007 de 2020 reconoce:

En definitiva, los derechos a la honra y el buen nombre ostentan tanto en instrumentos internacionales como en el ordenamiento constitucional interno, un reconocimiento expreso. El primero, que busca garantizar la adecuada consideración o valoración de una persona frente a los demás miembros de la sociedad, ante la difusión de información errónea o la emisión de opiniones tendenciosas que producen daño moral tangible a su titular. El segundo, dirigido a proteger la reputación o el concepto que de un sujeto tienen las demás personas, ante expresiones ofensivas e injuriosas, o la propagación de informaciones falsas o erróneas que distorsionen dicho concepto.

\subsection{El derecho a la imagen}

A diferencia del derecho a la honra y al buen nombre, el derecho a la imagen no está taxativamente señalado en la Constitución; no obstante, sí se ha dicho que proviene del derecho fundamental al reconocimiento de la personalidad jurídica (artículo 14), como también ha sido resaltado por Corredoira (2018), quien lo identifica como un derecho integrante de los derechos de la personalidad.

Así, la misma Corte Constitucional ha concluido que la imagen es un derecho fundamental autónomo derivado de la dignidad humana y relacionado con el libre desarrollo de la personalidad, que comprende desde la autodeterminación frente a la sociedad en que se convive, hasta el derecho de disponer la utilización de la imagen propia por terceros (Sentencia T-628 de 2017). De tal suerte, este derecho se vulnera cuando se adquiere y publica una imagen sin consentimiento de su titular.

\subsection{El derecho a la intimidad}

Este derecho mantiene un reconocimiento desde la Declaración Universal de Derechos Humanos (artículo 12), el Pacto Internacional de Derechos Civiles y Políticos (artículo 17) y el Pacto de San José de Costa Rica (artículo 11), que confluyen en la noción de la Carta Política (artículo 15). 
A partir de allí, surge la interpretación vigente — por casi tres décadas- de la Corte Constitucional por la que el derecho a la intimidad pretende impedir que trasciendan al conocimiento público actos que legal y moralmente una persona desea mantener en privado. En efecto, la intimidad también podrá ser familiar, dadas situaciones que solamente interesen a esa célula social. Por tanto, su núcleo esencial será la existencia y goce de la privacidad del sujeto, exenta de la intervención estatal o social (Sentencia T-007 de 2020, citando a las Sentencias T-603 de 1992 y C-881 de 2014).

De tal suerte, este derecho se verá vulnerado cuando: a. Se entrometa materialmente en aspectos personales de una persona, quien ha decidido reservarlos para sí; b. Se divulguen hechos privados que aunque ciertos, no son susceptibles de ser ventilados; $y$, c. Se presente información falsa relacionada con hechos íntimos que no corresponden a la realidad (Sentencia T-007 de 2020).

\subsection{Alcance del patrimonio moral en personas fallecidas}

Sobre estas bases conceptuales, la misma Corte Constitucional colombiana ha fijado que los derechos a la honra, al buen nombre, a la intimidad y a la imagen, pueden ser reconocidos a los familiares de una persona fallecida, siempre que el núcleo familiar resulte afectado con actos que atenten contra la integridad moral del difunto o del grupo familiar. Bajo esta interpretación, se concluyó así:

La familia de la persona directamente concernida goza de legitimidad para ejercer la acción de tutela en defensa de los enunciados derechos fundamentales. Desde luego, supuesto necesario de la prosperidad de la acción en tales casos es el de que las especies divulgadas no correspondan a la verdad, razón por la cual lesionan de manera infundada e injusta el patrimonio moral de la familia. No se vulneran los aludidos derechos si las afirmaciones que se hagan están fundadas en sentencias judiciales o en hechos innegables respecto de los cuales no cabe ninguna duda. Pero, en cambio, sí se afectan y en grado sumo, cuando se propalan sin fundamento versiones o informaciones en virtud de las cuales se juega con la honra, la fama, el buen nombre o el honor de una persona. En cuanto al derecho a la intimidad, este se ve afectado de todas maneras, así resulte verdadero lo que se difunde, cuando toca con la esfera íntima inalienable de una persona o de su familia, a menos que se cuente con la autorización de los involucrados. (Sentencia T-259 de 1994).

Es por lo anterior que los familiares de la persona fallecida se encuentran legitimados para salir en su representación, cuando se detente una afectación a su patrimonio moral, con instrumentos legales como lo sería una acción constitucional de tutela, una acción de responsabilidad civil extracontractual o incluso mediante denuncias penales, lo cual implica que el alcance del patrimonio moral del difunto se extiende al ámbito familiar.

Desde una perspectiva del derecho americano, se ha dicho que los familiares de las personas fallecidas mantienen el derecho a controlar el estado de la memoria y a prevenir la explotación no autorizada por otros, restringiendo el derecho a la publicidad (Binder, 2002). 
En la misma óptica, en España se ha dicho que aunque la personalidad se extinga con la muerte, la memoria del fallecido constituye una prolongación que debe ser tutelada jurídicamente, en atención al buen nombre del difunto, extensible a sus familiares cercanos (Minero Alejandre, 2018).

Con todo, consideramos que el concepto constitucional de la integridad moral en personas fallecidas tiene en cuenta - cuando menos - los derechos a la honra, al buen nombre, a la imagen y a la intimidad, extensible a los familiares cercanos del difunto, cuando se afecte la esfera íntima de la persona o de su familia, lo cual los legitima para salir en su defensa.

Dicho lo anterior, podemos avanzar al capítulo final de esta investigación, en la que propondremos la punibilidad de los delitos de injuria y calumnia en personas fallecidas.

\section{La punibilidad de los delitos de injuria y calumnia cometidos en contra de personas fallecidas}

Como se expuso, la integridad moral de las personas subsiste incluso después de su fallecimiento, lo cual legitima a sus familiares directos para alegar judicialmente su defensa, cuando se detente una vulneración de esta clase de patrimonio personal del sujeto o de su núcleo familiar.

Esto habilita la posibilidad de entablar acciones de tutela - como ocurre en la Sentencia T-007 de 2020 y demás fallos citados-, o de acciones de indemnización por vía de responsabilidad civil extracontractual, pero además, pensamos que resulta viable el iniciar el aparato judicial desde la jurisdicción penal, precisamente a partir de los delitos de injuria y calumnia (Ley 599 de 2000, artículos 220-221).

Así, lo primero que tendremos en cuenta es que ambas conductas penales son querellables, lo cual implica que para su procesabilidad (Ley 906 de 2004, artículo 70) requiere la presentación de una querella; teniendo la calidad de querellante legítimo la víctima de la conducta punible (ibíd., artículo 71).

Es importante resaltar que en caso de que la querella no sea presentada por la víctima, subsiste el archivo de las diligencias por parte de la misma Fiscalía General de la Nación o de estar en una etapa posterior, habilitaría la preclusión bajo la causal de imposibilidad de iniciar o continuar con el ejercicio de la acción penal (ibíd., artículo 332, núm. 1).

Pues bien, el legislador penal ha contemplado la posibilidad de que la víctima del delito querellable fallezca, dando lugar a que la figura del querellante legítimo transmute a sus herederos o familiares directos (ibíd., artículo 71), que a nuestro criterio, abre la posibilidad de que en casos de delitos de injuria y calumnia cometidos contra personas fallecidas, sus familiares puedan entablar la querella garantizando el requisito de procesabilidad.

Para ejemplificar la situación, podemos pensar en que se hagan públicamente imputaciones deshonrosas en contra de una persona fallecida, o que se le impute falsamente la comisión de una conducta punible, situaciones ambas que vulneran la integridad moral del difunto, y 
por esta vía, la de sus familiares, generando consecuencialmente la categoría de querellantes legítimos en estos últimos.

Desde este punto de vista, el difunto adquiere la calidad de sujeto pasivo del delito, y sus familiares directos los de víctimas, en el entendido que "la titularidad de los derechos a la honra, al buen nombre, a la imagen y a la intimidad recaen también sobre una persona fallecida, razón por la cual los familiares de esta pueden solicitar su protección" (Sentencia T-007 de 2020).

Lo anterior, debido a que con tal difamación se transgrede el bien jurídicamente tutelado de la integridad moral, que como se ve, no queda únicamente en el fallecido, sino que irradia a sus familiares. De tal suerte, la interpretación propuesta sobre los delitos de injuria y calumnia exalta su punibilidad con independencia de que el sujeto pasivo de la conducta punible haya fallecido.

Resulta importante recordar que en el Código Penal colombiano de 1890, no se reconocía la punibilidad de la injuria cometida sobre personas fallecidas en los términos del artículo 759, cuyo tenor literal señalaba: "Los autores de escritos históricos no pueden ser acusados de injurias respecto de personas muertas" (Bernate Ochoa, F. y Sintura Varela, F., 2019, p. 142); no obstante, el paso del tiempo permitió una visión más amplia como lo concluye el profesor José Antonio Saiz Cantero (1957), cuando al hacer una revisión de la entonces codificación penal colombiana, consideró que "los autores de escritos históricos no pueden ser acusados de injurias inferidas a personas muertas salvo cuando dé a conocer sus faltas o vicios puramente privados o domésticos" (p. 114).

Como lo hemos afirmado, la normativa vigente (Ley 906 de 2004, artículo 71) junto con las conclusiones recientes de la Corte Constitucional (Sentencia T-007 de 2020), permiten extender la punibilidad de la injuria y calumnia cometidas sobre personas fallecidas cuando materialmente se infiera la lesión al bien jurídico de la integridad moral.

Con lo anterior queremos decir que, siempre y cuando objetivamente se determine el cumplimiento de los elementos estructurales de los tipos de injuria y calumnia, será viable considerar su punibilidad identificando a una persona muerta como sujeto pasivo, teniendo 6 meses contados a partir del hecho lesivo (Ley 906 de 2004, artículo 73) para presentar la respectiva querella por parte de los herederos en la calidad adquirida de querellantes legítimos, conforme lo proponemos.

Por lo expuesto, queda en claro que a partir de las consideraciones de la Corte Constitucional colombiana frente a la tutela del patrimonio moral de las personas fallecidas y a favor de sus familiares directos, serán punibles los delitos de injuria y calumnia cometidos en contra de personas muertas, atribuyéndose por ello la calidad de querellantes legítimos a los miembros cercanos de la familia del difunto bajo la calidad de víctimas y al difunto mismo como sujeto pasivo sobre el que recae la conducta punible. 


\section{Conclusiones}

Con el presente artículo se efectuó un repaso del concepto del bien jurídico de la integridad moral, en el que bajo una óptica jurisprudencial actualizada, se pudo determinar su fragmentación en los derechos a la honra, al buen nombre, a la imagen y a la intimidad, como un todo que debe garantizarse en procura del patrimonio moral.

Esta integridad moral en personas fallecidas, desde una noción constitucional, debe tener en cuenta los precitados derechos conformantes del patrimonio moral, que per se, deben reconocerse a los familiares directos del difunto siempre que se atente su esfera personal o la de su familia, lo cual los legitima para entablar acciones legales en su defensa, que como se dijo, pueden ir desde un tipo de acción constitucional de tutela o de responsabilidad civil extracontractual, hasta poner en ejercicio a la jurisdicción penal.

A partir de lo anterior y al tener en cuenta que la calidad de querellante legítimo se transfiere a los familiares directos de la persona fallecida - como lo señala el Código de Procedimiento Penal (artículo 71) - para cumplir con la querella como requisito de procesabilidad, resulta dable considerar la punibilidad de los delitos de injuria y calumnia que se cometan sobre personas fallecidas, entendiendo al difunto como sujeto pasivo y a su familia como víctimas, cuando materialmente se infiera la lesión al bien jurídico de la integridad moral.

Por lo expuesto, resultan punibles estas conductas cometidas contra personas fallecidas, atribuyéndose por ello la calidad de querellantes legítimos a los miembros cercanos de la familia del difunto bajo la calidad de víctimas y al difunto mismo como sujeto pasivo sobre el que recae la conducta delictiva.

\section{Referencias}

Asamblea Nacional Constituyente. (1991). Constitución Política de la República de Colombia. Gaceta Constitucional, n. ${ }^{\circ} 116$. Recuperado de https://bit.ly/3qsOdL0

Bernate Ochoa, F., \& Sintura Varela, F. (Eds.). (2019). Código penal de la República de Colombia. Ley 19 de 1890 (del 19 de octubre). Bogotá, Colombia: Editorial de la Universidad del Rosario. https://doi. org/10.12804/cp9789587843835

Binder, W. (2002). Publicity rights and defamation of the deceased: Resurrection or R.I.P? DePaul Journal of Art, Technology \& Intellectual Propetry Law, 12 (2), 297-332. Recuperado de https://via.library. depaul.edu/jatip/vol12/iss2/3

Colombia. Ley 599 de 2000. Por la cual se expide el Código Penal. Diario Oficial, n. ${ }^{\circ} 44.097$. Recuperado de http://www.secretariasenado.gov.co/senado/basedoc/ley_0599_2000.html

Colombia. Ley 906 de 2004. Por la cual se expide el Código de Procedimiento Penal. Diario Oficial, n. ${ }^{\circ}$ 45.658. Recuperado de http://www.secretariasenado.gov.co/senado/basedoc/ley_0906_2004.html

Corredoira, L. (2018). The Right of One's Own Image in the Recent Cases of Sexual Harassment in Film Industry: Applying the European Theory of Concentric Circles to Celebrities (In Particular, Women). Journal of Information Policy, 8, 381-400. https://doi.org/10.5325/jinfopoli.8.2018.0381 
Minero Alejandre, G. M. (2018). La protección post mortem de los derechos al honor, la intimidad y propia imagen y la tutela frente al uso de datos de carácter personal tras el fallecimiento. Pamplona, España: Editorial Thompson Reuters Aranzadi.

Organización de los Estados Americanos (ozA). (1969). American Convention of Human Rights. "Pact of San José, Costa Rica". Recuperado de https://bit.ly/3et2hBw

Saiz Cantero, J. A. (1957). El contenido sustancial del delito de injurias. Anuario de Derecho Penal y Ciencias Penales, 10 (1), 85-120. Recuperado de https:/dialnet.unirioja.es/descarga/articulo/2772391.pdf

Sentencia T-603 de 1992. Corte Constitucional de Colombia. Magistrado Ponente: Simón Rodríguez.

Sentencia C-417 de 2009. Corte Constitucional de Colombia. Magistrado Ponente: Juan Carlos Henao Pérez. Recuperado de https://www.corteconstitucional.gov.co/relatoria/2009/C-417-09.htm

Sentencia C-489 de 2002. Corte Constitucional de Colombia. Magistrada Ponente: Martha Victoria Sáchica Méndez. Recuperado de https://www.corteconstitucional.gov.co/relatoria/2002/C-489-02.htm

Sentencia T-123 de 1994. Corte Constitucional de Colombia. Magistrado Ponente: Vladimiro Naranjo Mesa. Recuperado de https://www.corteconstitucional.gov.co/relatoria/1994/T-123-94.htm

Sentencia T-259 de 1994. Corte Constitucional de Colombia. Magistrado Ponente: José Gregorio Hernández Galindo. Recuperado de https://www.corteconstitucional.gov.co/relatoria/1994/T-259-94.htm

Sentencia T-471 de 1994. Corte Constitucional de Colombia. Magistrado Ponente: Hernando Herrera Vergara. Recuperado de https://www.corteconstitucional.gov.co/relatoria/1994/T-471-94.htm

Sentencia T-411 de 1995. Corte Constitucional de Colombia. Magistrado Ponente: Alejandro Martínez Caballero. Recuperado de https://www.corteconstitucional.gov.co/relatoria/1995/t-411-95.htm

Sentencia T-714 de 2010. Corte Constitucional de Colombia. Magistrada Ponente: María Victoria Calle Correa. Recuperado de https://www.corteconstitucional.gov.co/relatoria/2010/T-714-10.htm

Sentencia C-881 de 2014. Corte Constitucional de Colombia. Magistrado Ponente: Jorge Ignacio Pretelt Chaljub.

Sentencia T-022 de 2017. Corte Constitucional de Colombia. Magistrado Ponente: Luis Guillermo Guerrero Pérez. Recuperado de https://www.corteconstitucional.gov.co/relatoria/2017/T-022-17.htm

Sentencia SP11143-2016. Corte Suprema de Justicia de Colombia. Magistrado Ponente: Luis Antonio Hernández Barbosa.

Sentencia T-628 de 2017. Corte Constitucional de Colombia. Magistrada Ponente: Gloria Stella Ortiz Delgado. Recuperado de https://www.corteconstitucional.gov.co/relatoria/2017/T-628-17.htm

Sentencia T-007 de 2020. Corte Constitucional de Colombia. Magistrado Ponente: José Fernando Reyes Cuartas. Recuperado de https://www.corteconstitucional.gov.co/relatoria/2020/T-007-20.htm

United Nations. General Assembly. (1948). The universal declaration of human rights. General Assembly. Resolution 217 A. Recuperado de https://www.un.org/en/about-us/universal-declaration-ofhuman-rights

United Nations. General Assembly. (1966). International covenant on civil and political rights. Recuperado de https://www.ohchr.org/en/professionalinterest/pages/ccpr.aspx 